\title{
Kronik Karın Ăgrısı Olan Çocuklardan Alınan Gaita Örneklerinde Helicobacter Pylori Gaita Antijeni Aranması Ve Endoskopik Biyopsi Örnekleriyle Karşılaştırılması
}

\author{
Comparison of Helicobacter Pylori Gaita Antigen Screening and Endoscopic \\ Biopsy Specimens From Children with Chronic Abdominal Pain
}

\author{
Mustafa YILMAZ, Suzan ATMACA, İ. Hanifi ÖZERCAN, Yaşar DOĞAN
}

Fırat Üniversitesi Tip Fakültesi Mikrobiyoloji ABD, Elazığ,Türkiye

Geliş tarihi: 07.03.2019 Kabul tarihi: 16.12.2019 DOI: 10.17517/ksutfd.536905

Özet

Amaç: Bu çalışmada; karın ağrısı veya endoskobi endikasyonu olan çocuk hastaların mide antrumundan alınan biyopsi örneklerinin patolojik inceleme, gaita örneklerinde ise H.pylori antijen varlığı araştırılarak, H.pylori kaset testinin tanıdaki etkinliğinin araştırılması amaçlanmıştır.

Gereç ve Yöntemler: Çocuk Gastroenteroloji polikliniğine karın ağrısı şikayeti ile başvuran, altı-on sekiz (6-18) yaşları arasındaelli (50) hastadan alınan gaita ve endoskobik biopsi örnekleri çalışma grubunda değerlendirilmeye alındı. Kontrol grubuna ise esas yakınması karın ağrısı olmayan altı-on sekiz (6-18) yaşları arasında elli (50) hastadan alınan gaita ve endoskobik biopsi örnekleri dahil edildi. Gaita örneklerinde karteks yöntemi ile H.pylori antijeni, Endoskobik biopsi örneklerinde ise Giemsa boyama yöntemi ile H.pylori basili araştırıldı.

Bulgular: Çalışma grubundaki 50 hastanın 47 (\%94)'sinin endoskobik biopsi örneğinde H.pylori(Giemsa boyama ile) pozitif saptanmıștır. Aynı hastaların 37 (\%74)'sinde ise H.pylori gaita antijeni pozitif bulunmuştur. Kontrol grubundaki 50 hastanın 14 (\%28)'ünün endoskobik biopsi örneğinde H.pylori pozitif bulunurken, aynı hastaların 3 (\%6)'ünde H.pylori gaita antijeni saptanmıştır. Çalışma ve kontrol grubu arsındakifark istatistiksel olarak $(\mathrm{p}<0.05)$ anlamlı bulunmuştur $(\mathrm{p}=0.000)$.

Sonuç: Çalışmada kullandığımız H.pylori gaita antijeni taramasının invaziv olmaması, ucuz, kolay uygulanabilir ve patolojik incelemeye yakın duyarlılıkta pozitif sonuç vermesi açısından H.pylori tespitinde kullanılmasının uygun olacağı kanaatine varılmıştır.

Anahtar Kelimeler: H.pylori, endoskobi, gaita antijen testi.

\footnotetext{
Abstract

Objective: The aim of our study; exploration of helicobacter pylori stool antigen in pediatric patients with abdominal painfull and the comparison with biopsy specimens.

Material and Method: In the study group were evaluated the stool and endoscopic biopsy samples that obtained from abdominal painfulfifty (50) patients between six (6) and eighteen (18) years old and applicant to Pediatric Gastroenterology Polyclinic. In the control group were evaluated the stool and endoscopic biopsy samples that obtained from fifty (50) patients, without abdominal painful ,between six (6) and eighteen (18) years old. In stool samples, H. Pylori antigen was investigated by karteks method. In endoscobic biopsy samples H. Pylori was investigated by Giemsa staining method.

Results: H. Pylori were positive in fourty seven $(47,94 \%)$ biopsi samples of patients in the study group by Giemsa stain. H. Pylori stool antigen were positive in thirty seven $(37,74 \%)$ samples of same patients.H. pylori were positive in the fourteen (14, 28\%) biopsi samples of patients in the control group by Giemsa stain. H. Pylori stool antigen were positive in the three $(3,6 \%)$ samples of same patients. The statistically difference was significant $(\mathrm{p}=0.000)$.

Conclusion:The H. Pylori stool antigen method used in this study is inexpensive, noninvasive, easy to apply and terms of positive results to give a sensitivity close to pathological examination. This method is appropriate to use in the detection of $\mathrm{H}$. Pylori infection. Keywords:H.pylori, endoscopy, stool antigen test.
}

Yazışma Adresi: Mustafa YILMAZ Fırat Üniversitesi Tıp Fakültesi Mikrobiyoloji ABD, Elazı̆̆ Tlf:04242370000/5324578608 Mail:yilmazm64@hotmail.com

ORCID No(Sirasiyla): 0000-0003-4385-6733, 0000-0003- 1357 -0478, 0000- 0002- 8781- 8838, 0000 -0001- 9738- 9611 


\section{GíRiş}

Helicobacter grubu içinde insan sağlığı açısından klinik önemi olan; Helicobacter pylori(H.pylori)'dir (1). H.pylori spiral şekilli gram negatif, bir kutupta çok sayıda flagellum içeren (4-6 adet) ve çok hareketli bir basildir (2). Dokuda spiral, kültürde basil veya kıvrık, kokumsu şekilde mikroaerofilik bir bakteri olup,katalaz ve oksidaz reaksiyonu pozitiftir (3).

Bugün H.pylori'nin dünya nüfusunun yarısını infekte ettiği kabul edilmektedir. Gelişmiş ülkelerden Avrupa ülkeleri ve Amerika Birleşik Devletleri(ABD)'inde çocukluk yaş grubunun \%0-5'inin,20 yaş civarındakilerin \%10-20'sinin,yetişkinlerin ise \%30-50'sinin H.pylori ile infekte olduğu bildirilmiştir. Gelişmekte olan ülkelerd eise prevalans 5-10 yaş arasında \%60-70'i, yetişkinlerde \%85-90'i bulmaktadır. Gelişmiş ülkelerde sosyoekonomik gelişmeye bağlı olarak H.pylori görülme sıklığındaki azalma, peptik ülser ve mide karsinomlarında da gözlenmiştir. Ülkemizde 14yaş altı çocuklarda 10yı lönceki oran \%78 iken, 2000yılında bu oran \%62 olarak bildirilmiştir. Bu bilgiler aynı zamanda infeksiyonun çocukluk çağında alındığını ve ileri yaşlara da taşındığını göstermektedir $(1,3,4)$.

H.pylori’nin insanda yaşayabildiği tek yer mide mukozasıdır. Midenin antrum mukozası bakterinin en sevdiği yerdir. Mide mukozasının nötrale yakın pH'daki mukus tabakası, bakterinin salgıladığı üreaz enziminin bakteriyi mide sıv1sındaki düşük pH'dan koruduğu, mikoorganizmanın yaşama olanağını arttırdığı bildirilmiştir. Bakteri, burada dokuya invaze olmadan yüzeyd eyaşar ve çoğalır. H.pylori'nin mukozalarda üreyerek mukozal değişikliklere, kronik aktif gastrit ve peptikülsere neden olduğu bildirilmiştir (5).

Tanıda kullanılan testler endoskobik biyopsi gerektiren invaziv tanı yöntemleri(histopatolojik inceleme,kültür,üreaz testi) ve invaziv olmayan yöntemler [üre solunum testi,serolojik testler, polimeraz zincir reaksiyonu(PZR),gaita antijen testi]'dir $(3,6)$. İnvaziv testlerden midenin farklı bölgelerinden alınan biyopsi örneklerinin histopatolojik olarak incelenmesi ile bakteri varlığı ve oluşan doku hasarı konusunda önemli bilgiler edinilebilmektedir. Histopatolojik incelemede sıklıkla hematoksilen-eozin boyama yöntemi, sonuç alınamayan olgularda Giemsa gib ibaşka bir boyama yöntemi kullanılmaktadır. Giemsa boyama daha hızlı ve ucuz olup yöntemin duyarlılığı hemotoksilen-eozine göre daha yüksek bulunmuştur. Kültürde; bakteri varlığı çok az olduğunda, gastritin yama tarzında olması durumunda veya biyopsinin yanlış bölgelerden alınması durumunda yalancı negatiflik görülebilmektedir. Bu nedenlerle Giemsa boyamanın duyarlılığının kültüre göre de daha yüksek olduğu bildirilmiştir. Ayrıca kültürün zaman alıcı ve pahalı biryöntem olması gibi dezavantajları da vardır. Histopatolojik incelemenin H.pyloritanısında duyarlılığı \%93-99, özgüllüğü ise \%95-99 olarak bildirilmiştir $(3,4)$.

Tanıda kullanılan noninvaziv testlerden olan gaitada antijen arama yöntemi, poliklonal veya monoklonal antikorlar kullanılarak, enzyme immunoassay metoduyla gaitada
H.pylori antijeninin bulunması esasına dayanır. Monoklonal antikor kullanılarak yapılan testin duyarlılığı (\%96) ve özgüllüğü (\%97),poliklonal antikor kullanılarak yapılan testin duyarlılığ1 (\%91) ve özgüllügüünün(\%93) daha yüksek olduğu bildirilmiştir. Tedavi başlandıktan iki hafta sonra gaitada H.pylori antijeni negatifleşmektedir. PPI, antibiyotik ilaç kullanımı ya da bizmut preparatları, $H$.pylori'yi baskılayabileceğinden, yanlış negatif sonuçlara sebep olabilmektedir. Buna bağımlı olarak gaitada antijen arama testleri tedavi sonrasında kullanıldığında duyarlılığ $1 \% 86$, özgüllüğü ise \%92'ye kadar düşmektedir $(4,5,7)$.

Bu çalışmada;karın ağrısı ve endoskobi endikasyonu olan çocuk yaştaki hastaların mide antrumundan alınan biyopsi örnekleri, Giemsa boyama ile H.pylori varlığ 1 yönünden araştırılmıştır. Aynı hastalardan alınan gaita örneklerinde H.pylori kaset testi ile antijen varlığı araştırılmış ve bu iki testten elde edilen sonuçlar karşılaştırılarak H.pylori kaset testinin tanıdaki etkinliğinin araştırılması amaçlanmıştır.

\section{GEREÇ ve YÖNTEMLER}

Çocuk Gastroenteroloji polikliniğine başvuran hastalardan karın ağrısı, dispepsi şikayeti ile başvuran 6-18 yaş arası 50 hastadan alınan gaita ve endoskobik biopsi örnekleri çalışma grubunda değerlendirilmeye alındı. Kontrol grubunda ise karın ağrısı ve spesifik bulguları olmayan, hastalarda çoğunlukla büyüme geriliği veya üst GİS kanaması olan6-18 yaş arası 50 hastadan alınan gaita ve endoskobik biopsi örnekleri değerlendirildi. Gaita örneklerinde karteks yöntemi ile H.pylori antijeni; endoskobik biopsi örneklerinde ise Giemsa boyama yöntemi ile H.pylori basili araştırıldı.

Çalışma ve kontrol grubundaki tüm olgulara üst Gastrointestinal Sistem (GİS) endoskobisi yapıldı. Endoskobi uygulamasindan önce hastalardan ve kontrol grubundan onam formu alındı. Üst GİS endoskobi ve biopsisi için 8 saat aç kalmaları istendi. Sedatif olarak midazolam kullanıldı. Boğaz aneztezisi için lidokain sprey formu kullanıldı. Endoskobik inceleme PENTAX EPK 100P marka cihaz ile yapıldı. Endoskobi esnasinda, 3 adet midenin antrum bölgesinden biyopsi alındı, örneklerden ikisi formole konularak patoloji laboratuarına gönderildi. Diğeri ependorfa alınıp eksi $21_{0}$ C'de muhafaza edildi. Antrumdan alınan biyopsi numuneleri Giemsa ile boyanarak H.pylor ivarlığ yönünden araştırıldı.

Gaitada antijen araştırmak amacıyla RTA marka ticari kit kullanıldı. Kit; kaset test,tampon (ekstraksiyon) tüpü ve kullanma rehberini içermekteydi. Kasetler ile ekstraksiyon tüpleri $2-8^{\circ} \mathrm{C}$ 'de ambalajı açılmadan muhafaza edildi. Alınan taze gaita örneklerinden kitin prospektüs talimatına uygun olacak şekilde çalışıldı. Hemen çalışılamayan örnekler $2-8^{\circ} \mathrm{C}$ saklanıp en fazla 48saatiçerisinde çalışıldı, ambalajı hasar görmüş testler kullanılmadı.

İstatistiksel değerlendirme için SPSSversiyonunun 21.0 paket programı tercih edildi. Çıkan sonuçlar bilgisayar ortamında paket programlar kullanılarak Ki-kare testine göre 
veri analizleri yapıldı ve $\mathrm{p}<0.05$ olan sonuçlar anlamlı olarak kabul edildi.

Bu çalışma,Fırat Üniversitesi Tıp Fakültesi Klinik Araştırmalar Etik KuruluBaşkanlığı'nca 11.03.2014 tarih ve 06 nolu Etik Kurulu kararı alınarak yapılmıştır. ÇalışmaFırat Üniversitesi Bilimsel Araştırma Projeleri Koordinasyon Birimi tarafından desteklenmiştir. Araştırmamıza dahil edilen tüm bireylere çalışmanın amacı ve yöntemi hakkında önceden bilgi verilerek onayları alınmıştır.

\section{BULGULAR}

Çalışma grubundaki 50 hastanın 21 (\%42)'i 6-12 yaşlarında, 29 (\%58)'u 12-18 yaşlarında olup, 24 (\%48)'ü erkek, 26 (\%52)'sı kadın idi. Hasta gurubunun 47 (\%94)'sinin endoskobik biopsi örneğinde H.pylori Giemsa boyama ile pozitif saptanmıştır. Aynı hastaların 37 (\%74)'sinde ise H.pylori gaita antijeni pozitif bulunmuştur. Kontrol grubundaki 50 hastanın 27 (\%54)'si 6-12 yaşlarında, 23 (\%46)'ü 12-18 yaşlarında olup, 21 (\%42)'i erkek, 29 (\%58)'u kadın idi. Bu 50 hastanın 14 (\%28)'ünün endoskobik biopsi örneğinde H.pylori (Giemsa boyama ) pozitif saptanmıştır. Aynı hastaların 3 (\%6)'ünde H.pylori gaita antijeni pozitif bulunmuş.Fark istatistiksel olarak $(\mathrm{p}<0.05)$ anlamlı ifade edilmiştir $(\mathrm{p}=0.000)$.

Çalışmaya alınan çalışma ve kontrol grubundaki hastaların şikayetlerine göre, yaş, cinsiyet ve H.pylori pozitiflik dağılımı tabloda verilmiştir (Tablo 1).

Yapılan Ki-kare analizinde kontrol ve hasta grubu arasında patoloji ve gaita sonuçları pozitifliği bakımından anlamlı fark olduğu $(\mathrm{P}<0.05)$, bunun yanında yaş,cinsiyet ve klinik şikayetler ile bu iki parametre arasında anlamlı bir ilişki olmadığ 1 tespit edilmiştir.

\begin{tabular}{|c|c|c|c|c|c|}
\hline \multirow{2}{*}{$\begin{array}{l}\text { Çalışma } \\
\text { Grubu }\end{array}$} & \multicolumn{4}{|c|}{ Kontrol Grubu } & \multirow[t]{2}{*}{ Toplam } \\
\hline & $\begin{array}{l}\text { Karın } \\
\text { ağrısı }\end{array}$ & $\begin{array}{l}\text { Bulantı- } \\
\text { Kusma }\end{array}$ & İshal & Kabızlık & \\
\hline $\begin{array}{l}\text { Yaş } \\
(6-12 / 12-18)\end{array}$ & $21 / 29$ & $9 / 16$ & $12 / 5$ & $6 / 2$ & $48 / 52$ \\
\hline $\begin{array}{l}\text { Cinsiyet } \\
(\mathrm{E} / \mathrm{K})\end{array}$ & $24 / 26$ & $7 / 18$ & $8 / 9$ & $6 / 2$ & $45 / 55$ \\
\hline $\begin{array}{l}\text { H.pylori } \\
\text { (gaita) } \\
\text { pozitifliği }\end{array}$ & 37 & 3 & - & - & 40 \\
\hline $\begin{array}{l}\text { H.pylori } \\
\text { (endoskopi) } \\
\text { pozitifliği }\end{array}$ & 47 & 5 & 8 & 1 & 61 \\
\hline $\begin{array}{l}\text { Toplam sayı } \\
\text { (n) }\end{array}$ & 50 & 25 & 17 & 8 & 100 \\
\hline
\end{tabular}

\section{TARTIŞMA}

H.pylorìnin tanısında çeşitli yöntemler kullanılmaktadır; $\mathrm{Bu}$ yöntemler; endoskopi sırasında alınan gastrik biyopsi örneğinin incelenmesini gerektiren invaziv yöntemler ile enkoskopi işlemi gerektirmeyen noninvaziv yöntemler olmak üzere iki ana gruba ayrılabilir. İnvaziv yöntemler arasında biyopsi den kültür, histolojik inceleme, hızlı üreaz testi yer almaktadır. İnvaziv olmayan yöntemler; serolojik testler, üre soluk testi, PZR ve gaitada H.pylori antijeni saptayan testleri içermektedir. H.pylori'nin tanısında altın standart yöntemin ne olduğu (veya neler olduğu) konusunda tam bir görüş birliğine varılamamıştır. Bu yüzden, teşhisin doğruluğunun artırılması için birden fazla yöntemin beraber kullanılması önerilmektedir. Tanıda hangi metotların kullanılacağına; fiyatı, kullanılan metodun erişilebilirliği, duyarlılık ve özgüllügü, hastanın mevcut durumu ve hastanın yaşı göz önünde bulundurularak karar verilir $(3,4,7)$.

Hui ve ark (8) Çin'de yaptıkları çalışmada toplam 56 hastada endoskopi sonucu, histopatoloji (Warthin-Starry boyama), üreaz ve kültür testi ile H.pylori varlığı araştırmış; H.pylori yönünden pozitif 27 hasta tespit etmişlerdir. H.pylori gaita antijeni tespit etmek için ImmunoCardSTATHpSA testi kullanılmış. Belirlenen gold kriterlere göre, kültürün tek başına ya da histoloji ile beraber üreazın pozitif olması durumunda hasta H.pylori pozitif, bütün testlerin negatif olması halinde ise H.pylori negatif olarak kabul edilmiştir. ImmunoCardSTATHpSA için sensitivite \%92.6, spesifisite \%88.5, PPD \%89.3, NPD \%92 bulunmuştur. H.pylori tanısı için gaita antijen testi, ImmunoCardSTATHpSA testinin basit, non-invaziv doğru sonuç veren bir test olarak kullanabileceğini ileri sürmüşlerdir.

Mete ve ark. (9) Namık Kemal Üniversitesi Tip Fakültesi Gastroenteroloji Kliniği endoskopi biriminde Mart 2010 ve Mart2013 tarihleri arasında gastroskopik araştırılması yapılan ve patolojik olarak sadece gastritis teşhisi alan yaş ortalaması 44.96 olan, (309'u erkek, 488'i kadın) toplam 797 hasta çalışmaya alınmış. Antrumdan alınan biyopsi örneği Giemsa ile boyanmış, Sydney sınıflamasına göre histolojik parametreleri tahlil edilerek H.pylori prevelansı \%73.7 olarak bildirilmiştir.

Uğraş ve ark. (10) karın ağrısı, gelişme geriliği, bulantı-kusma, üst GİS kanaması şikayeti ile gelen 5-17 yaş arası 357 hastaya endoskopi ve üre nefes testi uygulamışlardır. Ülserli hastaların \%80.8'inde H.pylori pozitif olarak bulunmuştur. H.pylori’nin ülkemizde ve çocuklarda sık rastlandığını çocuklarda gastrit ve ülserin yaygin görüldüğünü belirtmişlerdir. Uygun görülen çocuk hastaların gastroenterolojik ve endoskopik olarak araştırılması gerektiğini iletmişlerdir.

Queiroz ve ark. (11) Ekim 2007-Temmuz 2011 tarihleri arasında (yaşları 6 ile 30 ay) çocuklardan 1323 örnek alınmış (Brezilya 415, Peru 908) üre nefes testi ile H.pylori gaita antijeni testini karşılaştırmış, H.pylori pozitif 627 örneğin, H.pylori gaita antijeni de pozitif bulunmuştur. Üre-nefes testi negatif olan 23 örnek, H.pylori gaita antijeni negatif, üre nefes testi pozitif olan 45 örnek te pozitif tespit edilmiştir. H.pylori enfeksiyonu teşhisi için üre nefes testi ile gaita antijen testinin uyumunun pozitif sonuç verme oranı \%94.9 olarak bildirilmiştir (11).

Schulz ve ark. (12)'nın yaptı̆̆ 1 çalışmada ise sanayileşmiş ülkelere yerleşmiş, gelişmekte olan ülkelerden gelen mülteci 
ve göçmenlerde H.pylorỉnin yüksek oranda görüldügünü, bu bölgelerde mide kanseri ve peptik ülser oranlarını araştırmak için gaita antijen testi kullanımının endoskopi ile k1yaslandığında düşük maliyetli uygun bir test olduğunu ileri sürmüşlerdir.

Antos ve ark. (13)'nın yaptığ 1 iki merkezli, (Münih ve Viyana) çalışmada yaş ortalaması 9.7 olan, Münih'te 118, Viyana'da 41 toplam 159 çocuk hasta ele alınmıs, referans test olarak kültür ve üre nefes testi uygulanmıştır. Hastaların 86 ’nda H.pylori pozitif bulunmuştur. Tedaviden önce H.pylori kaset testinin sensitivitesi ve spesifitesinin her ikisi de \%88.1 olarak hesaplanmıs. 6-8 haftalık bir tedaviden sonra aynı prosedürün tekrarlanmasıyla elde edilen sensitivite oranları ise \%88.9'a, spesifite oranı\%93.9’a yükselmiştir. H.pylori varlığının değerlendirilmesi için gaita antijen testi kullanımının ucuz, kolay, uygun bir noninvaziv alternatif yöntem olduğunu savunmuşlardır.

Bizim çalışmamız Ekim 2014-Eylül 2015 tarihleri arsında hastanemizin çocuk gastroenteroloji polikliniğine başvuran, karın ağrısı şikayeti olan ve olmayan 50’er kişilik 2 gruptan oluşan 6-18 yaş arlığındaki çocuk hastalardan alınan gaita ve endoskobik biopsi materyali üzerinde yapıldı. Bu çalışmada endoskobik biopsi örneğinin Giemsa ile boyanarak H.pylori varlığını arştırmak ve aynı hastaların gaita örneğinde H.pylori antijenini karteks yöntemiyle araştırıp sonuçların karşılaştırılması amaçlandı. Çalışma grubundaki 50 hastanın 21 (\%42)'i 6-12 yaşlarında, 29 (\%58)'u 12-18 yaşlarında olup, 24 (\%48)'ü erkek, 26 (\%52)'sı kadın idi. Bu 50 hastaların 47 (\%94)'sinin endoskobi örneğinde H.pylori Giemsa boyama ile pozitif saptanmışken aynı hastaların 37 (\%74)'sinde ise H.pylori gaita antijeni pozitif bulunmuştur. Kontrol grubundaki 50 hastanın 27 (\%54)'si 6-12 yaşlarında, 23 (\%46)'ü 1218 yaşlarında olup, 21 (\%42)'i erkek, 29 (\%58)'u kadın idi. Kontrol gurubunun 14 (\%28)'ünün Endoskobi örneğinde H.pylori Giemsa boyama ile pozitif iken aynı hastaların 3 (\%6)'ünde H.pylori gaita antijeni pozitif saptanmıştır. Fark istatistiksel olarak $(\mathrm{p}<0.05)$ anlamlı bulunmuştur $(\mathrm{p}=0.000)$.

Hasta gurubunun 47'sinde paolojik inceleme ile (\%94) H.pylori saptanmışken, aynı hasta grubundan alınan gaita örneklerinde RTA marka ticari kit ile yapılan H.pylori antijen taramasında ise 37 hastada (\%74) pozitiflik saptanmıştır. Kontrol grubu olarak alınan aynı yaş grubu ve değişik klinik yakınmaları olan 50 kontrol hastasında ise patolojik inceleme sonucu 14 olguda, gaita antijen testi ile 3 olguda H.pylori pozitifliği gözlenmiştir.

Konunun yeni ve önemli oluşu epidemiyolojik ve tanı kriterleri için yapılan çalışmaların tam belirgin ve yeterli olmayışı, yurt dışında ve ülkemizde farklı yöntemlerin kullanılmasına ve tartışılmasına neden olmuştur.

Yapılan değerlendirmeler sonucu çalışma ve kontrol grupları arasındaki farkın gaitada antijen arama testinde daha belirgin olmak üzere istatistiksel olarak anlamlı olduğu net olarak gözlenmiştir. Çalışmada kullandığımız H.pylori gaita antijeni taramasının invaziv olmaması, ucuz olması, kolay uygulanabilir olması ve patolojik incelemeye yakın duyarll1ıkta pozitif sonuç vermesi açısından H.pylori ve enfeksiyonu tespitinde kullanılmasının uygun olduğu kanaatine varılmıştır.

Çıkar çatışması ve finansman beyanı: $\mathrm{Bu}$ çalışmada çıkar çatışması yoktur ve finansman desteği alınmamıştır.

\section{KAYNAKLAR}

1. Beşışık F. Helicobacter İnfeksiyonları. İliçin G, BiberoğluK, Süleymanlar G, Ünal S (editors). İç Hastalıkları. 3. Baskı, Ankara: Güneş Kitabevi; 2012: 2934-6.

2. Brooks GF, Carroll KC, Butel JS, Morse SA, Mietzner TA, (Editors), Yenen OŞ (çeviri editörü). Tibbi Mikrobiyoloji. 26. Baskı, İstanbul: Nobel Tip Kitabevleri; 2014: 261-2.

3. Ustaçelebi Ş. Temel ve Klinik Mikrobiyoloji. 1. Bask1, Ankara: Güneş Kitabevi; 1999: 536-40.

4. Tünger Ö. Helicobacter pylori İnfeksiyonları. İnfeksiyon Dergisi 2008; 22: 107-15

5. Altındiş M, Özdemir M. Helicobacter Pylori ve Tanısı. Kocatepe Tip Dergisi 2003; 2: 1-12.

6. Atherton CA, Blaser NJ. Infectious diseases. In: Charles M. Wiener, Cynthia D. Brown, Anna R. Hemnes (editors). Harrison's Principles of Internal Medicine. Chapter 151. Helicobacter pylori infections. 18 thed. United States of America: The Mc Graw-Hill Companies; 2012: 1261-6.

7. Usta Y, Özen H. Helicobacter pylori enfeksiyonu. Çocuk Sağlığ ve Hastalıkları Dergisi 2007; 50: 136-45.

8. Li YH, Guo H, Zhang PB, Zhao XY, Da SP. Clinical value of Helicobacter pylori stool antigen test, ImmunoCardSTATHpSA, for detecting H.pylori infection. World J Gastroenterol. 2004 Mar 15;10(6):913-4.

9. Mete R, Oran M, Güneş H, ve ark. Tekirdağ bölgesinde Helicobacter pylori prevelansı ve patolojik parametrelerin çok yönlü analizi; literatür ile güncelleme. Genel Tip Dergisi 2014; 24: 1-6.

10. Uğraş M, Alan S. Çocuklara yapılan üst gastrointestinal sistem endoskopilerinin sonuçlarının değerlendirilmesi. F.Ü. Sağlık Bilimleri Tip Dergisi 2012; 26: 31-4.

11. Queiroz DMM, Saito M, Rocha GA, et al. Helicobacter pylori Infection in Infants and Toddlersin South America: Concordance between $\left[{ }_{13} \mathrm{C}\right]$ Urea Breath Testand Monoclonal H.pylori Stool Antigen Test. J Clin Microbiol 2013; 51: 3735-40.

12. Schulz TR, Mc Bryde ES, Leder K, Biggs BA. Using stool antigen to screen for Helicobacter pylori in immigrants and refugees from high prevalence countries is relatively cost effective in PLoS One. 2014 Sep 30;9(9):e108610

13. Antos D, Crone J, Konstantopoulos N, Koletzkol S. Evaluation of anovel rapid one-step immunochromatographicassay for detection of monoclonal Helicobacter pylori antigen in stool samples from children. J Clin Microbiol 2005 Jun;43(6):2598-601. 